\title{
MODERN ROUTES TO EXPLORE CONCRETE'S COMPLEX PORE SPACE
}

\author{
PIET STROEVEN AND ZHANQI GuO \\ Faculty of Civil Engineering and Geosciences, Delft University of Technology, Stevinweg 1, 2628CN Delft, \\ The Netherlands \\ e-mail: z.guo@tudelft.nl \\ (Accepted June 29, 2006)
}

\begin{abstract}
This paper concentrates on discrete element computer-simulation of concrete. It is argued on the basis of stochastic heterogeneity theory that modern concurrent-algorithm-based systems should be employed for the assessment of pore characteristics underlying durability performance of cementitious materials. The SPACE system was developed at Delft University of Technology for producing realistic schematizations of realcrete for a wide range of other particle packing problems, involving aggregate and fresh cement, and for the purpose of exploring characteristics in the hardened state of concrete, including of the pore network structure because of obvious durability problems. Since structure-sensitive properties are involved, schematization of reality should explicitly deal with the configuration of the cement particles in the fresh state. The paper concentrates on the stereological and mathematical morphology operations executed to acquire information on particle size, global porosity, and on distribution of porosity and of the connected pore fraction as a result of the near neighbourhood of aggregate grains. Goal is to provide information obtained along different exploration routes of concrete's pore space for setting up a pore network modelling approach. This type of methodological papers is scarce in concrete technology, if not missing at all. Technical publications that report on obtained results in our investigations are systematically referred to.
\end{abstract}

Keywords: concrete, discrete element computer-simulation, mathematical morphology, particle dispersion, porosity, stereology.

\section{INTRODUCTION}

Concrete is a particulate material on different levels of the microstructure. It is also referred to as macroscopically heterogeneous material, although the stochastic heterogeneity involved is a feature of sampling and not of the material itself. Nevertheless, in combination with the complexity of the material structure, this tremendously complicates studies of material structure, as we will see later.

Durability problems are imminent all over the world. Transport through pore space of water containing harmful substances is in many cases causing the concrete or its reinforcement to gradually deteriorate. So, pore space has been and still is targeted in major research efforts. Experimental studies generally relied on structural information obtained from (thin) section images by qualitative or quantitative microscopy, by Mercury Intrusion Porosimetry (MIP) and Wood's metal porosimetry (Scrivener, 1989; Lange, et al., 1994; Wang and Diamond, 1995; Willis, 1998; Diamond, 2000). An overview of the various approaches and a discussion of the major differences in their output is given in $\mathrm{Hu}$ and Stroeven (2006). This paper will illustrate by data on computer-simulated concrete how the geometrical statistical features of materials structure required for setting up pore network modelling approaches for durability purposes could be obtained by modern stereological and mathematical morphology methods.

\section{METHODOLOGICAL ASPECTS}

Global porosity is the most obvious and at least partly useful descriptor for characterizing the concrete material for the intended purpose. The socalled interfacial transition zones (ITZs) around all aggregate grains are more recently subjected to investigations, since the generally higher porosity in these zones are suspected of predominantly governing global transport characteristics of the material (Stroeven and Stroeven, 2001b). When dealing with composition features of material structure, this releases the pressure of working with representative area elements (RAEs) for which stochastic heterogeneity has been reduced to acceptable proportions. In a comparative 
study of local porosity (porosity associated with elements smaller than RAE) as a function of hydration time, sampling at an equal sampling sensitivity level (= constant ratio of sample and RAE sizes - both increase with hydration time), was leading to identical Gaussian distribution curves, as demonstrated in Fig. $1 \mathrm{~b}$. This confirms (stochastic) heterogeneity to be a sampling property and not a material characteristic feature. For equal field sizes, the results are camouflaged by the stochastic heterogeneity effect (Fig. 1a), which can lead to incorrect conclusions (Hilfer, 1992; Biswal et al., 1998; Hu and Stroeven, 2005a,b,d).

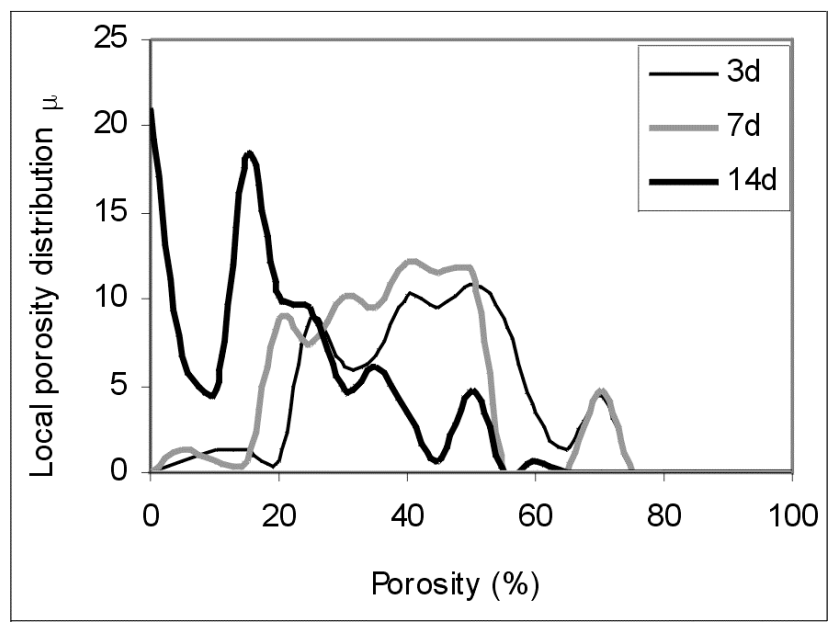

a)

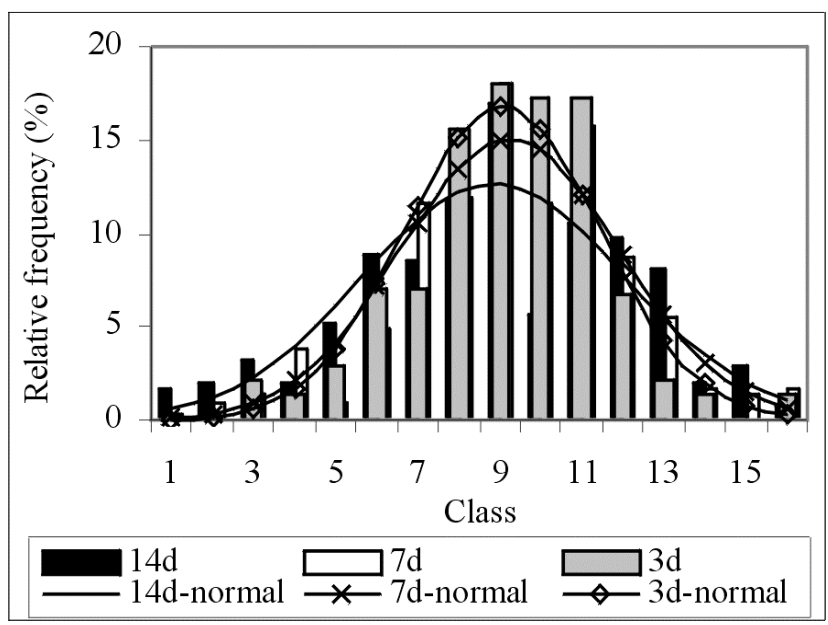

b)

Fig. 1. a) Local porosity distribution $\mu$ for cement paste with $w / c=0.6$ at 3, 7 and 14 days of hydration, respectively, at constant linear field size $L=19 \mu \mathrm{m}$. b) Conventional histograms of relative frequency of occurrence in porosity for the same pastes. The experimental values are indicated as columns and the approximated normal distribution curves are shown as continuous lines. Data are for similar sampling sensitivity and are normalized for porosity decline during hydration.
Factually, stochastic heterogeneity theory (Freudenthal, 1965; Holliday, 1966) demonstrates that information obtained on structure-sensitive properties from descriptors of configuration-sensitive nature will be biased when based on sub-representative designs (Stroeven, 2003; $\mathrm{Hu}$ and Stroeven, 2005b), as schematically illustrated in Fig. 2. The probability density functions (or histograms) of repeated similar observations on configuration-sensitive features of material structure are indeed skewed to the left, as demonstrated by Fig. 3, showing three nearest neighbour surface-to-surface (NNSSS) probability density functions for the unhydrated cement nuclei of one-year old cement pastes of different cement finenesses (indicated by the Blaine number in $\mathrm{m}^{2} / \mathrm{kg}$ ) and with Rosin-Rammler particle size distribution function (Breugel, 1991; Stroeven, 1999). An illustrative example from another research project dealing with jammed aggregate particles is presented in Table 1.

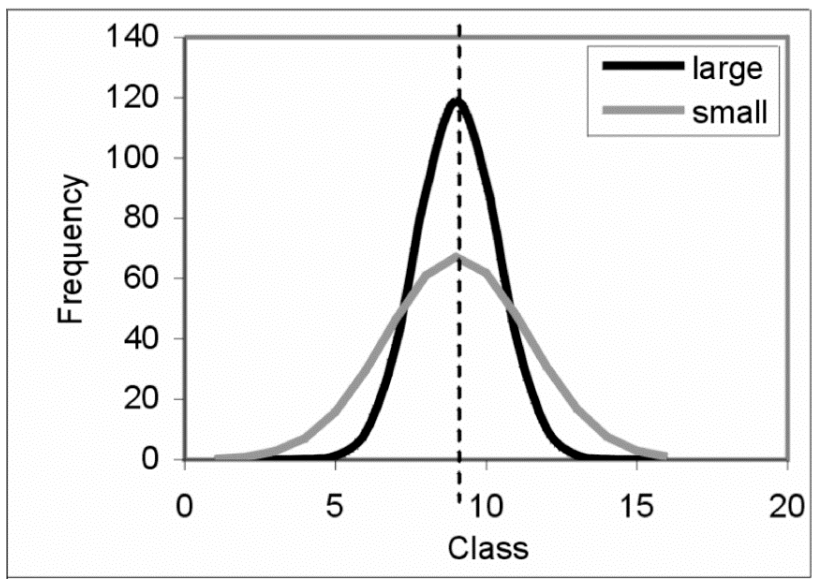

a)

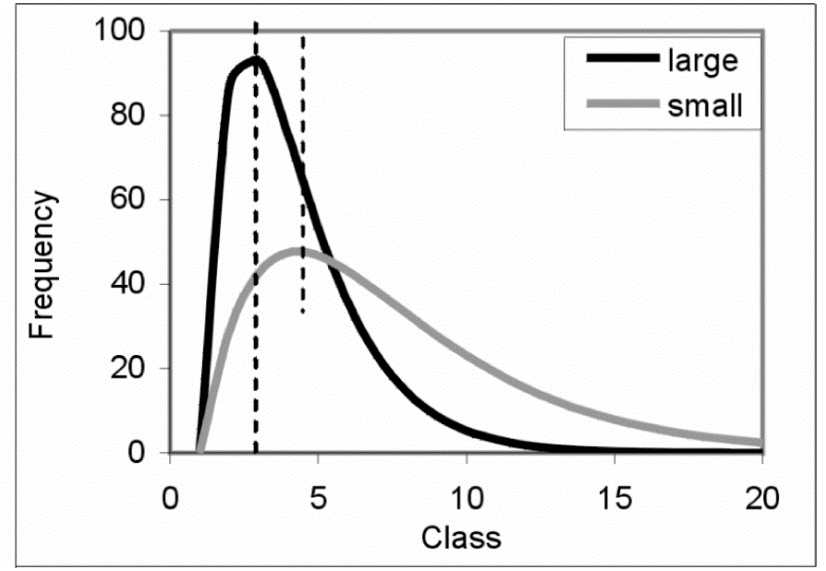

b)

Fig. 2. Frequency histograms of composition (a), and of configuration property (b) of "large" and "small" field images with respect to structural dimensions, say, maximum grain size. Number of fields is 400 . Histograms are smoothed for illustrative purposes. 


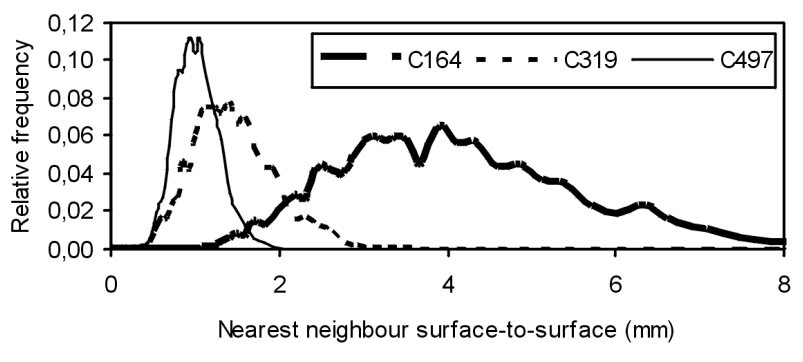

Fig. 3. Skewed distribution probabilities of NNSSS in three types of one-year-old cement pastes $(w / c=0.2)$. Mode and mean values undergo shifts when the image size is modified (He et al., 2006).

Hence, sub-RAE sampling leads to results that are biased to an unknown degree, since the linear dimensions of the RAE are different for different descriptors. In a sub-RAE approach - which is the common situation in concrete technology - results can only be used for a comparative analysis under the restrictive condition of maintaining a constant ratio of linear dimensions of field images and of relevant RAEs (Stroeven, 2003; Hu and Stroeven, 2005b). A condition seldom realized in quantitative pore analysis in concrete technology. Also observation sensitivity should be adjusted to changes in the RAE size.

Table 1. Biases in averages of nearest neighbour surface-to-surface spacing distributions in jammed aggregate due to sampling on different levels (all dimensions in $\mathrm{mm}$ ) (Chen et al., 2006).

\begin{tabular}{ccc}
\hline Container size & Mean spacing & Mode spacing \\
\hline 253 & 0.1083 & 0.0751 \\
92.6 & 0.1062 & 0.0993 \\
46.3 & 0.0989 & 0.1640 \\
\hline
\end{tabular}

Analytical models that use the experimentally obtained information on porosity are mostly crudely schematizing the complex reality of the highly tortuous partly connected network structure of pore space. Such simplified models suffice to predict transport rate through a block of concrete, since we deal here with a structure-insensitive property of the material. For structure-sensitive properties the schematization of reality would be too crude. Structural research should provide the information needed for the design of more sophisticated models. The experimental route is demonstrated not impassable, but time-consuming and treacherous, as indicated.

Alternatives are provided by simulation strategies that yield so-called compucrete. This encompasses concretes produced as schematization of real concretes (=realcrete) by simulation algorithms. Compucrete becomes available in this way for investigations in the virtual reality of the computer. Images of sections and of thin sections can be subjected to quantitative image analysis. Geometrical statistical descriptors can additionally be applied to study interesting threedimensional (3D) global geometric features of the compucrete, such as the 3D nearest neighbour surfaceto-surface distribution (Chen et al., 2006; Chen, 2007). Of course, the investigations have also to fulfil the discussed requirements imposed by the stochastic heterogeneity theory.

Available physical computer simulation methods for forming granular packing of hard particles can be placed in two distinctive groups. The first group, based on so-called concurrent algorithms, involves the densification of a fixed number of particles. The SPACE system, on which our studies rely, is the sole existing example in this category in present-day concrete technology (Stroeven, 1999; Stroeven and Stroeven, 1996; 1999; 2000; 2001a). The second group is based on sequential algorithms. Most computer simulation approaches fall in this second category (Diekämper, 1984; Roelfstra, 1989; Breugel, 1991; Bentz et al., 1993; Meakawa et al., 1999). They generate granular packing of spheres or particles with other idealized shapes by sequential random addition, SRA. Particles of a pre-determined assembly are sequentially placed on randomly selected positions in a container of fixed size progressing from the largest to the smallest particles. When overlap occurs, new positions are generated until violation of physical conditions is avoided. Volume fractions significantly less than found in reality, either for aggregates or for cement particles in the high performance range, can be realized only. The so-called jammed state (Williams and Philipse, 2003), particularly relevant for aggregates in concrete, cannot be achieved at all. More dramatically, according to Williams and Philipse is "any relation between these SRA packings and an experimental granular packing at best tenuous." Simple stochastic reasoning also leads to the conclusion that SRA systems will generate too uniform particle dispersions in which particle clustering is suppressed. Figs. 4 and 5 convincingly demonstrate these features.

Some upgraded SRA systems are described in the literature, such as the one in which particles that tend to overlap are subjected to random shifts (Williams and Philipse, 2003). This paper pursues presenting and discussing some of the results of our trips through pore space in virtual concrete produced by discrete element, concurrent algorithm-based SPACE system. 
So far we have taken for granted that physical modelling would be the only way to "schematizing reality". It certainly is the most intuitive approach, and received therefore prime attention in engineering efforts in concrete technology. Reference should be given, however, to probabilistic models as a schematization of reality with operational potential. Once such a model is found to represent reality sufficiently good (considering the afore-mentioned fundamental relationship between type and degree of schematization and degree of structure-sensitivity of the objected property), the characteristics of the model are known. This is not the case with a physical simulation. All probabilistic models start from a Poisson process that is also at the basis of most physical modelling approaches. This paper not intends to go into any detail of such approaches, despite the claim to offer potentially more promising routes than provided by physical modelling ones (Dequiedt et al., 2001).

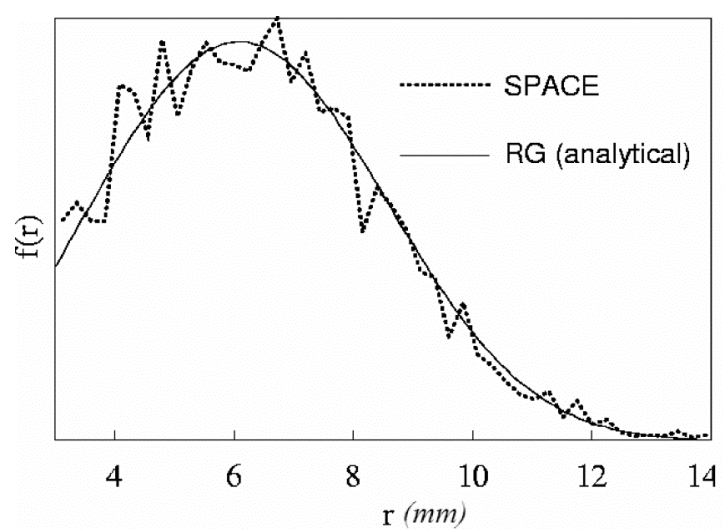

a)

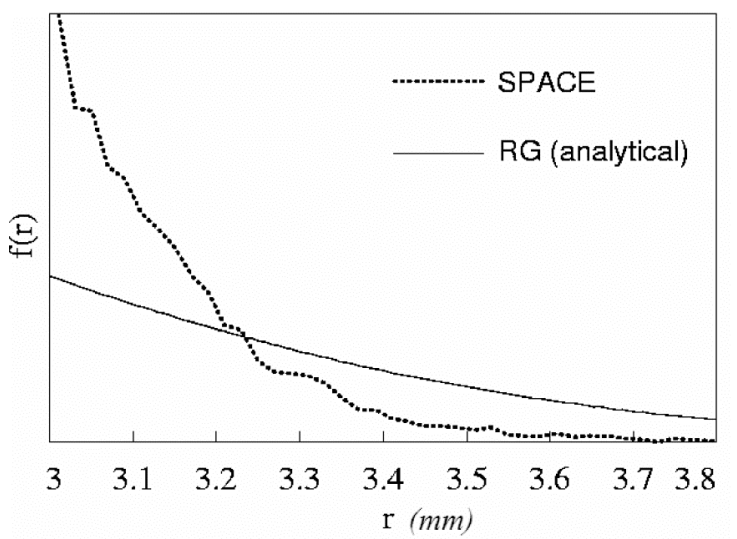

b)

Fig. 4. Deviations between predictions on nearest neighbour center-to-center density distributions, $f(r)$, at $1 \%$ (a) and $30 \%$ (b) by volume of aggregate obtained by random generator $(R G)$, respectively, by concurrent algorithm based (SPACE) computer simulation systems (Stroeven and Stroeven, 1996).

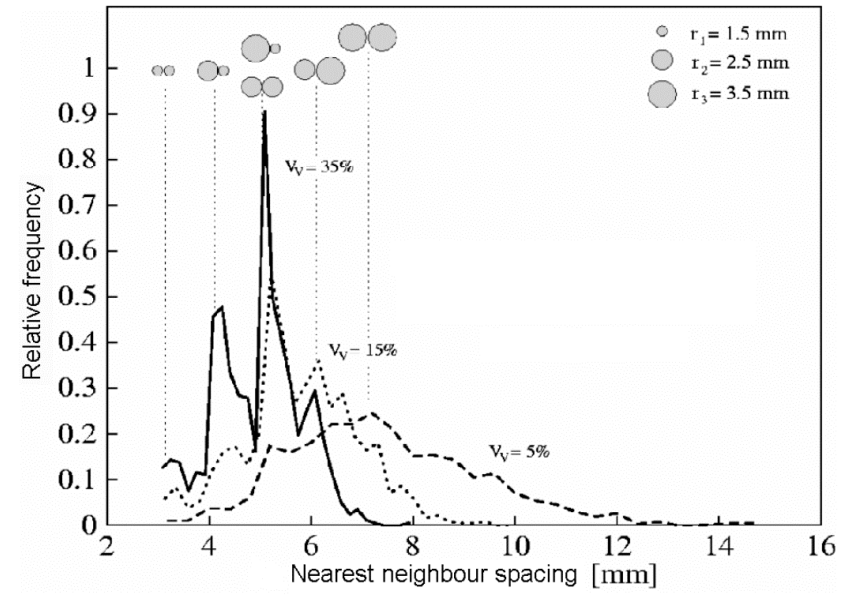

Fig. 5. Nearest neighbour center-to-center distributions in aggregate mixtures composed of three particle sizes $(3,5$ and $7 \mathrm{~mm})$ at total volume contents of 5,15 and $35 \%$. At increasing volume density, particle clustering becomes an apparent phenomenon (Stroeven and Stroeven, 2000).

\section{SPACE-PRODUCED PORE SPACE}

The SPACE system, developed at Delft University of Technology, realizes compaction by a dynamic algorithm, which is also supposed to imitate the production stage of the material. The forces added to the particles can be manipulated, so that "sticky" particle contacts (or particle repulsion) during the production of the model material can be simulated. Also gravity effects can simply be included. This dynamic (Newtonian) simulation mechanism has no significance after completion of the simulation, hence, is not connected with the rheological properties of the cementitious model material (Stroeven and Stroeven, 1997; 1999; 2001a). SPACE is based on spherical particles only. However, at present a new SPACElike system (HADES) is in development allowing the use of arbitrarily shaped grains (Fig. 6a). This is to account for particle shape effects that seem to have more serious impact on packing than so far assumed in concrete technology. The schematization will also involve shape, since this has been demonstrated to influence the density in the jammed state. River gravel and broken rock aggregates will compact to different densities in the jammed state at equal grading (obtained by sieving). In Philipse (1996) this has been quantitatively evaluated for sphero-cylinders.

Because inter-particle contacts in SPACE were impulse-based, they occurred in an infinitesimal small timeframe. Hence, forces between particles could not exist. As a consequence, force-based experiments, such as densification under pressure, could not be performed. With the new discrete element package, 
particles can be of any shape and contacts are forcebased rather than impulse-based. The surface of objects is no longer described by a mathematical function (such as in case of a sphere), but by a set of interconnected surface elements. In this way any shape can be described. Fig. 6b, showing a twodimensional dense packing of a variety of objects, illustrates the versatility of this approach. Particle densification by shaking, flow, or impact constitute but a few examples of the simulation possibilities. Three-dimensional simulations are possible as well. An article has been recently submitted for publication to the WEB journal Forma, giving access to two MPG movies (Stroeven et al., 2006b). One presents the simulation of typical dynamic granular effects leading to size segregation, the so-called Brazil nut effect. The second movie illustrates that it is possible to simulate particles packing subjected to high stresses, something that was not possible with SPACE. The interested reader is referred to this forthcoming publication.

The compucrete is produced in limited quantities in cubic moulds. Basically, containers with rigid walls are used, or with so-called periodic boundaries (Stroeven and Stroeven, 1996). The first situation conforms to a moulded aggregate, or to cement pocketed between surfaces of aggregate grains. The second type of boundary conditions is used to simulate bulk material. Recently, we have used a mixed situation, whereby two rigid surfaces were combined with four periodic ones. This is constructed from a cube with periodic boundaries in which halfway a rigid surface is embedded (Figs. 7 and 8).

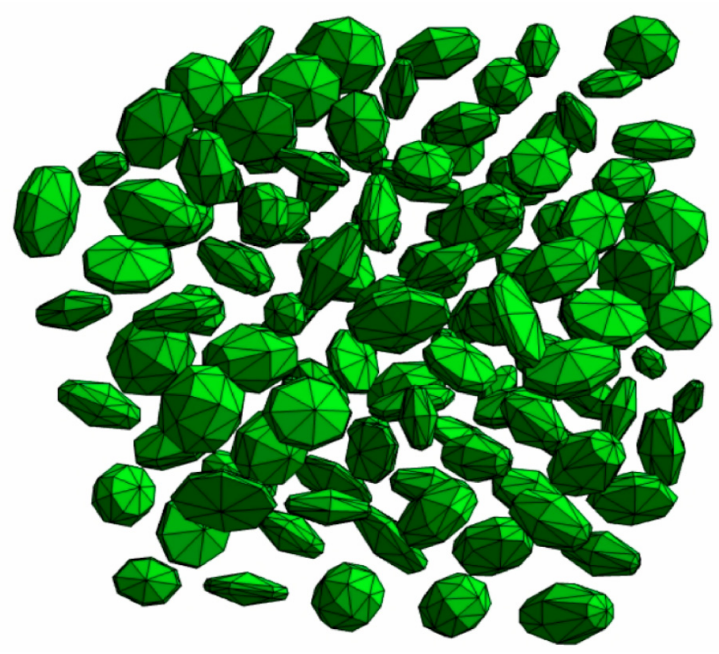

a)

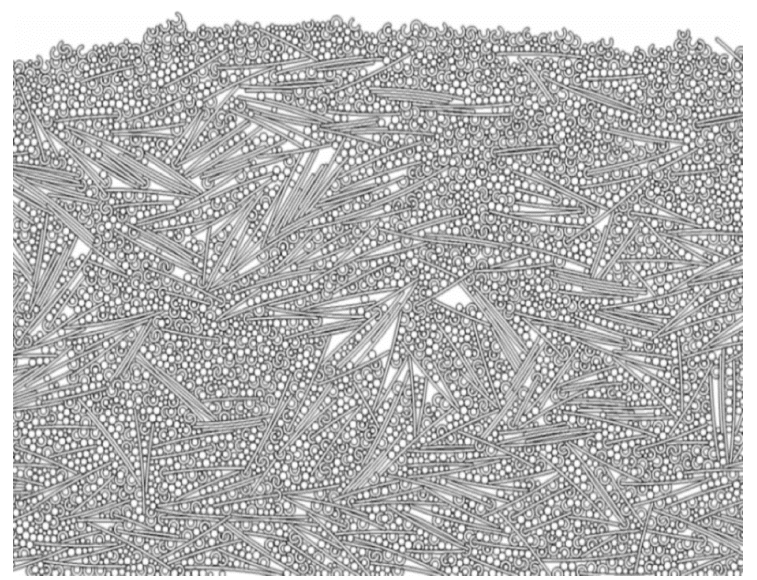

b)

Fig. 6. a) Arbitrarily shaped particle assembly for $3 D$ simulation of particulate system. b) Two-dimensional dense packing of a variety of objects and dispersed pores.

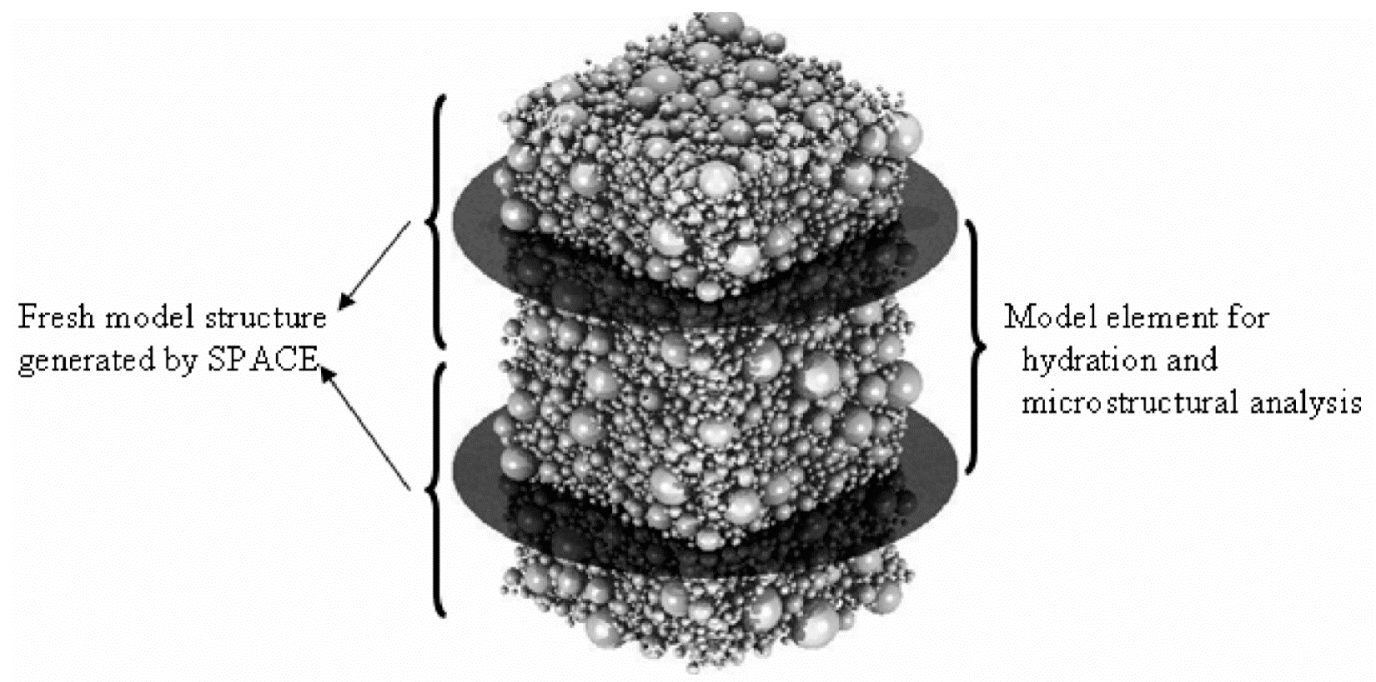

Fig. 7. Fresh model cement paste structure with semi-rigid boundary conditions. 


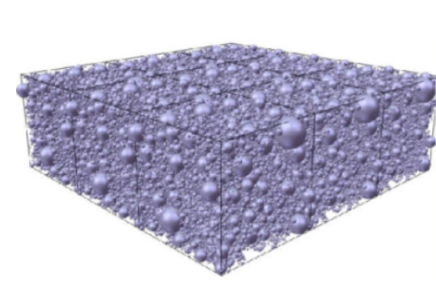

Periodic boundaries

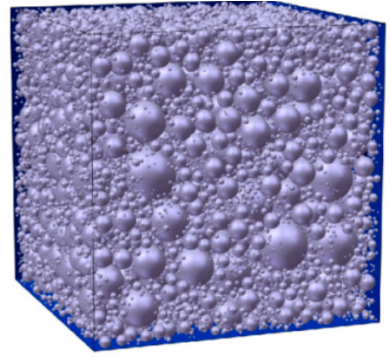

Rigid boundaries

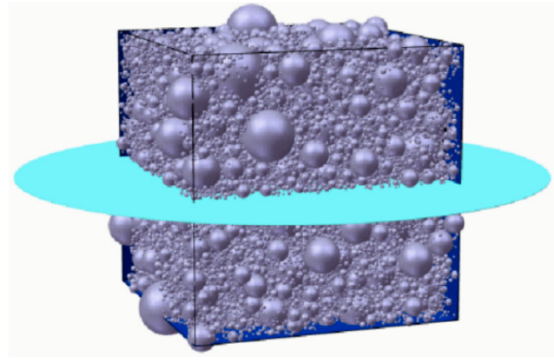

Semi-rigid boundaries

Fig. 8. Fresh model cement paste structures produced with different boundary conditions.

\section{SIMULATION OF CEMENT PASTE AND ANALYSIS ROUTES}

Virtual compucrete in the fresh state has been produced in our research by SPACE in all cases. For hydration of these particulate systems, two routes were followed, namely

1. Hydration by SPACE, with subsequent structural analysis by quantitative image analysis on single sections, and by application of mathematical morphology operators (Stroeven, 1999; Stroeven and Stroeven, 1996; 1997; 2001b; Hu, 2004).

2. Hydration by SRA-based HYMOSTRUC3D. The hydration algorithms in both systems are quite similar, but Ye (2003) developed algorithms for $3 \mathrm{D}$ reconstruction on the basis of dense serial sectioning. The latter strategy was followed for pore space analysis (Chen et al., 2006; Chen, 2007).

Ye also studied pore structure by computer simulation but produced the fresh state by HYMOSTRUC3D as well. It can be considered a third possible route. Thereupon, he applied his 3D reconstruction system to the improperly dispersed particle system, so unbiased results can be expected for composition properties only. Further, he assessed the pore size distribution by systematically filling up pore space by spheres of increasing size, starting from a predefined point. This leads to results depending on the position of the starting point (Ye at al., 2003). Alternatively, in route 1) we have determined star volume in randomly selected points on section images of pore space (Gundersen and Jensen, 1985).
Simulations were realized in containers with periodic, rigid and mixed boundary conditions. Rigid surfaces allow the study of gradient structures in cement particle packing in the fresh state, so-called size segregation, as shown in Fig. 9. Size segregation has also been expressed in other geometric terms, like volume fraction, grading or spacing of grains. The general pattern is that of the smallest particles migrating closest to the interface surface. The next largest fraction has its highest volume density a bit further away, a.s.o. The size segregation phenomenon is at the basis of the formation around the aggregate grains of ITZs, which have paramount impact on mechanical and durability performance of the material. Of course, this segregation phenomenon can only fully manifests itself when proper production conditions (workability and compaction energy) are provided (Fig. 10).

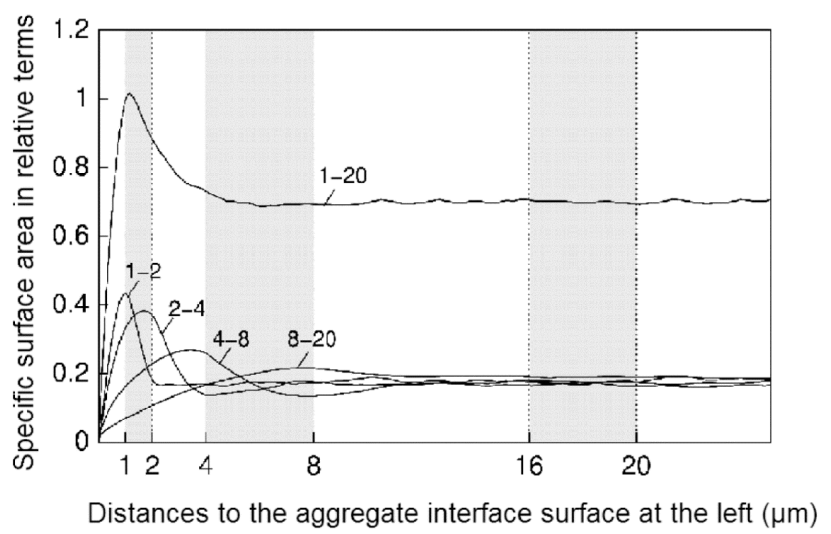

Fig. 9. Size segregation in fresh state of model cement, grain sizes between 1 and $20 \mu \mathrm{m}$. Specific surface area is in relative terms given on the vertical axis for the size fractions and the total mixture. 
Gradient structure in the mean free spacing in the fresh state is qualitatively maintained in the hardened state (Fig. 11). Hence, this also holds for the relatively high "porosity". This is the procedure followed in route 1). Fig. 11 points toward a concentration of porosity in a thin layer very close to the surface of aggregate grains.

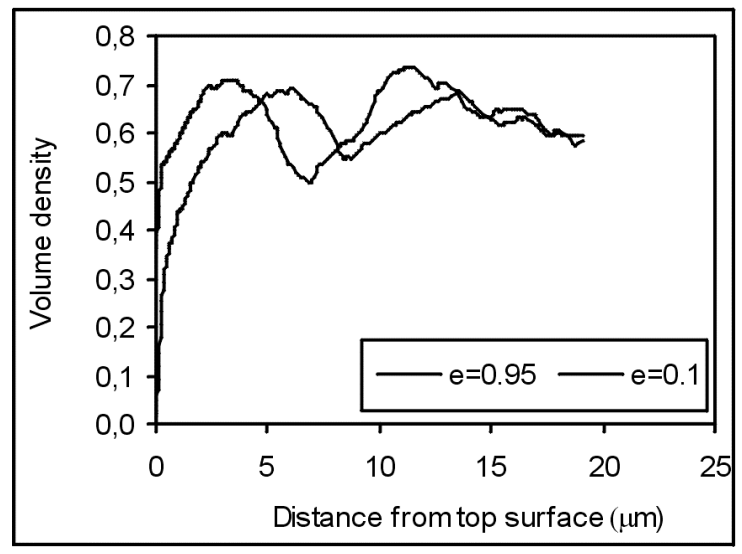

a)

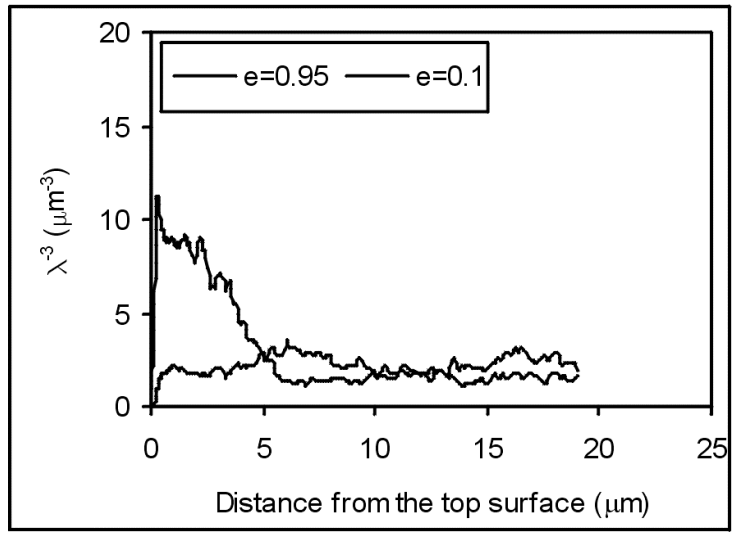

b)

Fig. 10. Effect of workability conditions on density a) and internal bonding capacity b) of fresh binder with discontinuous grading near the aggregate grain surface. The parameter e represents the energy dissipation during compaction. High value of $e$ means a better workability. Van der Waals physical bonding is supposedly proportional to $\lambda^{-3}$, whereby $\lambda$ stands for the mean free spacing (Hu et al., 2006b).

\section{ASSESSMENT OF POROSITY, PORE SIZE AND PORE DEPERCOLATION}

Intriguing studies were performed according to the earlier described routes on concrete porosity. Pores have highly irregular shapes, and build up a complex spatial network structure. Model cements of equal fineness lead to different total porosities despite mixed with the same amount of water when aggregate grain surfaces enclose the paste, or are more remote. Hence, even total porosity is not a purely composition property.

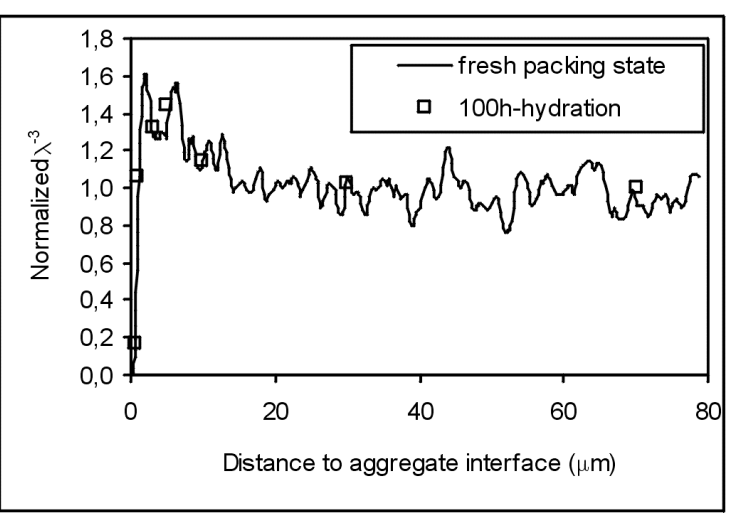

Fig. 11. Normalized physical bonding (cf. Fig. 10) plotted against distance to the aggregate interface in the fresh packed model concrete with $w / c=0.3$, cement specific surface area of $340 \mathrm{~m}^{2} / \mathrm{kg}$ (left), and in the hardened concrete hydrated for 100 hrs (right) (Hu and Stroeven, 2005c).

Simulated data are shown in Fig. 12. A fully enclosed cement pocket is simulated at the centre; the aggregate surfaces are remote at the left. So, periodic boundaries are employed in the simulation. A mixed situation is shown at the right, with two parallel surfaces (=aggregate grain surfaces) and four periodic ones (remote aggregate surfaces).

Total porosity is a global measure that has engineering relevance when pore space is uniformly distributed. Whether this is reflecting reality has been studied along route 2). SPACE-generated fresh cements were hydrated by HYMOSTYRUC3D (basically, similar as in SPACE). 3D reconstruction by serial sectioning was thereupon accomplished. Hence, total porosity and connected fraction of it were determined as function of the degree of hydration in cubical elements of diminishing size obtained from the original ones by successive removal of surface layers (Fig. 13). These parameters are plotted at $75 \%$ of ultimate degree of hydration for these cubical elements of reduced size in Fig. 14. Obviously, total porosity and even stronger, connected fraction of porosity, form gradient structures in the ITZ, with maximum values at the aggregate grain surfaces. 


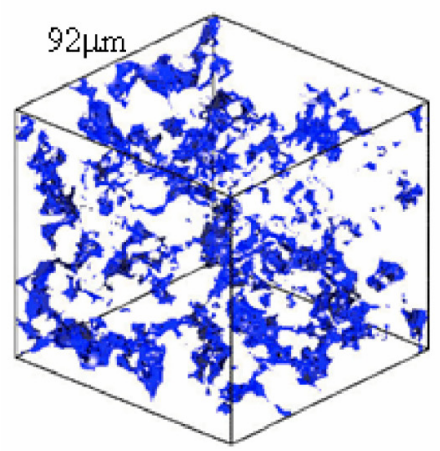

Periodic (Porosity $=1.24 \%$ )

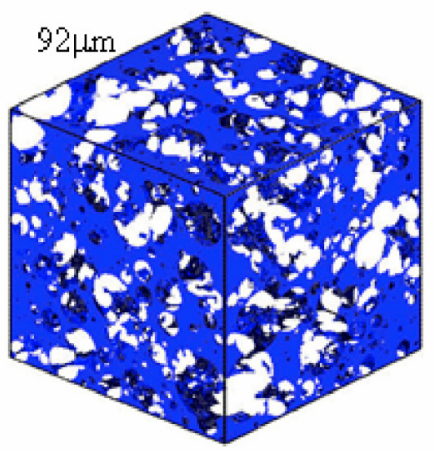

Rigid (Porosity $=2.92 \%$ )

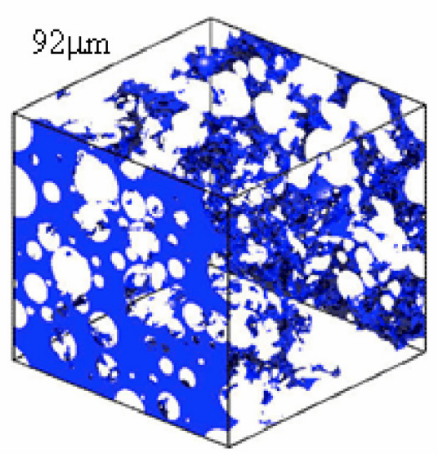

Semi-rigid $($ Porosity $=2.22 \%$ )

Fig. 12. Total porosity for different boundary conditions at ultimate degree of hydration (fineness $300 \mathrm{~m}^{2} / \mathrm{kg}$, water to cement ratio $=0.3)$ (Chen, 2007; Stroeven at al, 2007).

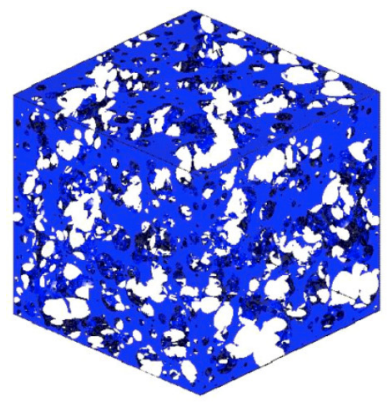

$184 \mu \mathrm{m}$

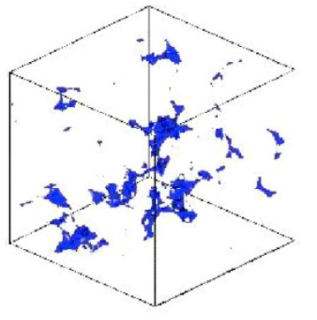

$100 \mu \mathrm{m}$

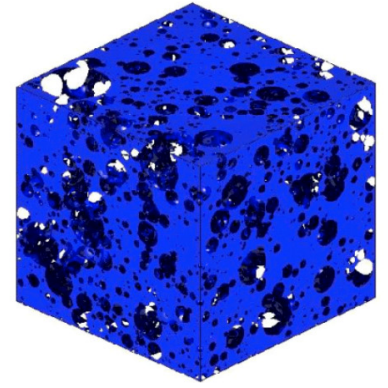

$202 \mu \mathrm{m}$

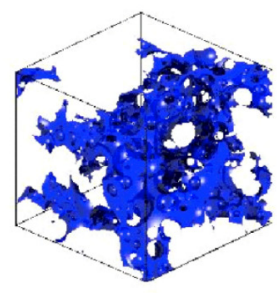

$100 \mu \mathrm{m}$

Fig. 13. Two cubes with rigid boundaries of fully hydrated cement pastes (left: Ultimate Degree of Hydration = 0.748; right: $U D H=0.991$ ) with water to cement ratio of 0.30 (left) and $w / c=0.50$ (right). Additionally, central cubes are displayed that result from successive removal of thin surface layers totalling the complete ITZ thickness. (Chen et al., 2006c; Chen, 2007).
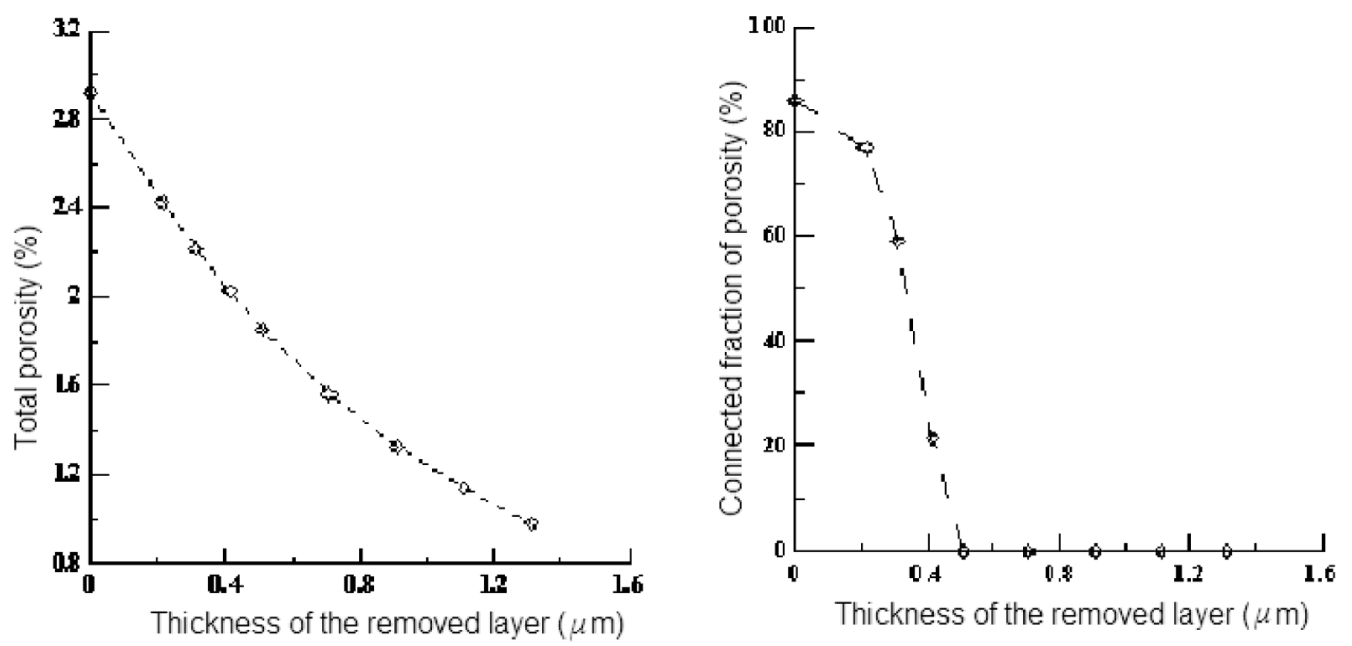

Fig. 14. Connected porosity is restricted to a narrower zone $(0.5 \mu \mathrm{m})$ in the ITZ of SPACE-generated compupaste $\left(w / c=0.3 ;\right.$ Blaine number $=300 \mathrm{~m}^{2} / \mathrm{kg}$ ) between aggregate grain surfaces (container walls) than total porosity (limited to zone of $2 \mu \mathrm{m}$ ) at about 75\% degree of hydration (DOH) (Chen et al., 2006c; Chen, 2007). 
The gradual depercolation of cement paste was described by local percolation probabilities in 1). The local percolation probability denotes the probability to find a continuous path through a sample of given size. In 2) the depercolation phenomenon was directly studied by $3 \mathrm{D}$ reconstruction. Fig. 15 presents the different local percolation probabilities for cement paste in different directions (Hu and Stroeven, 2005a). Pore space in the sample is fully connected into all Cartesian directions for $\lambda_{3}=1$ and is completely depercolated for $\lambda_{0}=1$. The $3 \mathrm{D}$ reconstruction results are presented in Fig. 16. Route 3) by Ye is obviously leading to biased results, however during the depercolation process configuration-sensitivity is declining, as can be expected. The final depercolation limit seems relatively configuration-insensitive. Results are in good agreement with those of Bentz et al. (1993).

With pore size distribution determined by way of the opening distribution technique according to Delfiner (1971) and Serra (1982) (Fig. 17), all the necessary pore characteristics are available for designing a proper network structure.

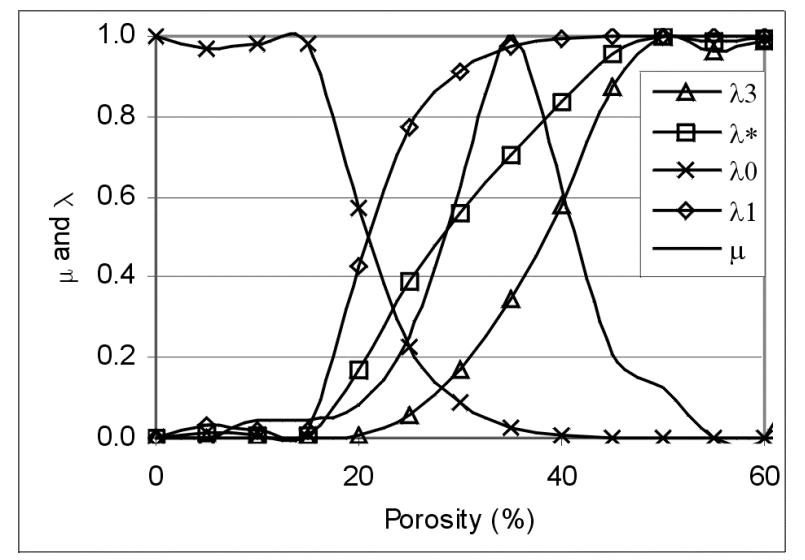

Fig. 15. Local porosity distribution $\mu$ and local percolation probabilities $\lambda_{\alpha}$ for cement paste with a $w / c=0.4$ at 3 days hydration, at the characteristic length scale $L=40 \mu \mathrm{m} ; \lambda^{*}$ represents the local percolation probabilities in $x, y$ and $z$ direction $\left(\lambda_{x}=\right.$ $\lambda_{y}=\lambda_{z}$ ) (Hu and Stroeven, 2003; 2005a,d).

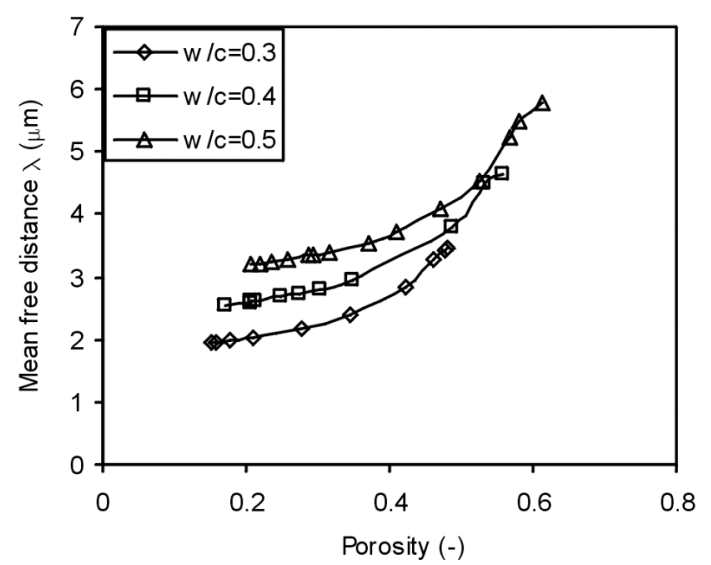

b)

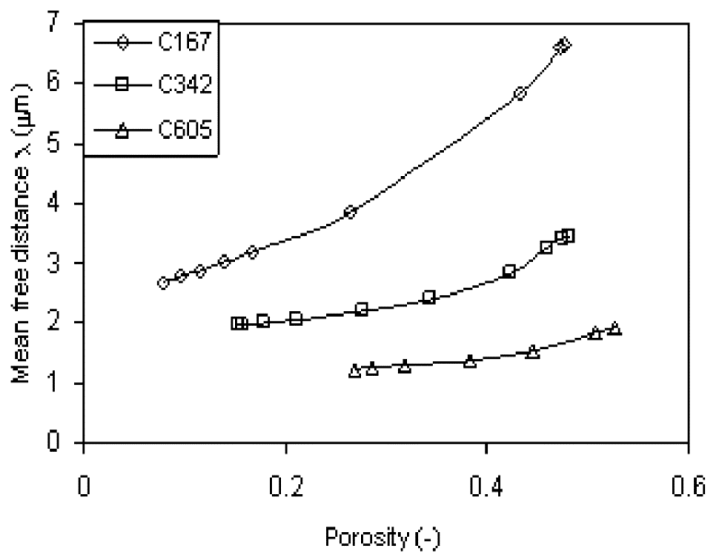

c)

Fig. 16. Depercolation process during hydration (plotted versus porosity) of model cement pastes simulated by HYMOSTRUC $3 D$ and by SPACE system a). The influences of $w / c$ ratio and cement fineness level on the depercolation process are reflected in b) and c), respectively. 


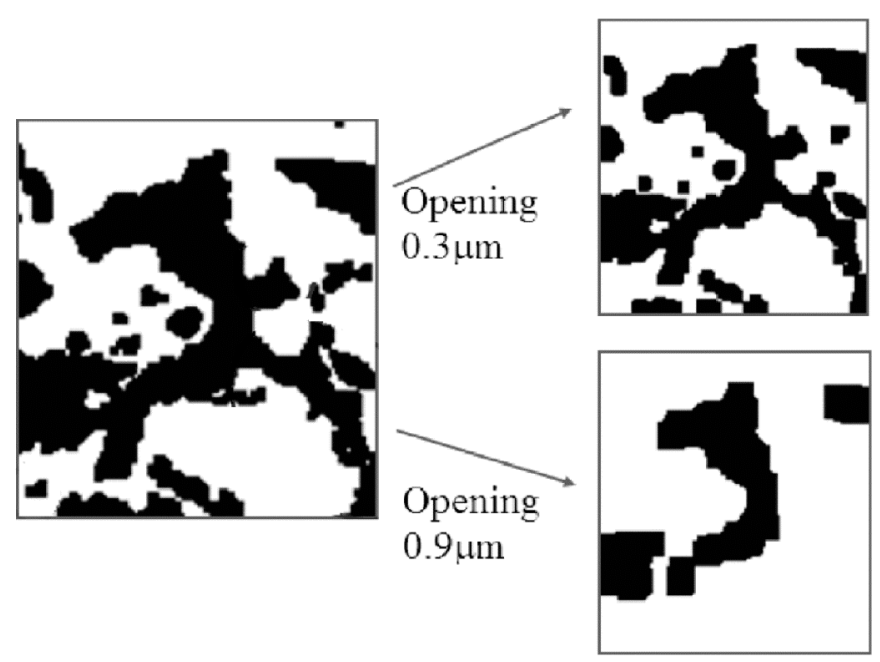

Fig. 17. Opening distribution by structuring elements of increasing sizes gives a sort of size classification. By opening with a structuring element of increasing size, regions are successively removed that contribute to the size range between the last two element sizes (Hu and Stroeven, 2006).

\section{PORE NETWORK MODELLING, DISCUSSION}

The given information on pore space characteristics points in the direction of a multiple connected pore network structure. This is also a schematization of realcrete, but a less crude one than mostly employed for durability performance predictions. The jammed state of the aggregate provides for interconnection possibilities of the thin layers with percolated pores that enrobe the aggregate grains. A cherry-pit model is proposed to simulate the connection areas (Stroeven et al., 2006b). The resulting incomplete connections probably yield the inkbottle effect in the network (Willis et al., 1998) that degenerate MIP measurements on pore size distribution (Diamond, 2000; $\mathrm{Hu}$ and Stroeven, 2005d). This would support the statement of Vogel (1997) that the way pores are interconnected may be even more important than pore size and connected fraction of porosity.

The fraction of total porosity that is percolated can be studied as indicated on either sections or by $3 \mathrm{D}$ reconstructions. Along these two different routes one can also obtain the size distribution of the pores that make up the transport system. Basically, this would be a logic approach, also used by Vogel and Roth (2001), Fatt (1956) and Friedman and Seaton (1996). The implementation of obtained data in the framework of such a pore network model for predicting certain transport characteristics of concrete were not targeted in this publication. It was pursued to demonstrate how the pore characteristics required for the design of such a network model could be and have been obtained along two different stereological routes. Of course, more systematic simulation work by concurrent algorithm-based systems is required to cover the full spectrum of technological parameters.

\section{CONCLUSIONS}

The application of concurrent algorithm-based discrete element simulation has been demonstrated essential for obtaining unbiased information. Only when this approach indicates that a low configurationsensitivity is involved (such as seemingly with the percolation threshold), SRA systems may be employed.

When configuration-sensitive features of material structure are studied, fields should be of representative size. This is generally not possible in quantitative microscopy. Obtained data can still be used in a comparative sense though, provided the field sizes are adjusted in proportion to imposed changes (in the present context by time, and technological parameters) of the RAE, and the observation sensitivity is equally adjusted to these changes. These are direct implementations of the stochastic heterogeneity theory.

Time-consuming and laborious $3 D$ reconstruction operations can yield the pore size and topology information required for construction of the pore network model. Pore size distribution should not be derived from dense filling of pore space by spheres of increasing size, starting from a pre-described point, as performed by Ye.

Economic stereological and mathematical morphology procedures also allow obtaining the required information for the pore network modelling 
design from sections. The pore size distribution can be obtained by application of star volume to random points, or by the opening operation. Mean free distance operator yields information on the location of the highly porous zone close to the aggregate grain surfaces. Local percolation probabilities of porosity provide the required topological information.

\section{REFERENCES}

Biswal B, Manwart C, Hilfer R (1998). Three-dimensional local porosity analysis of porous media. Physica A 255:221-41.

Bentz DP, Garboczi EJ, Stutzman PE (1993). Computer modeling of the interfacial transition zone in concrete. In: Maso JC, ed. Interfaces in Cementitious Composites. London: E\&FN Spon, 107-16.

Breugel K van (1991). Simulation of hydration and formation of structure in hardening cement-based materials. $\mathrm{PhD}$ Thesis, Delft University of Technology, Delft.

Chen H (2007). Numerical modelling of ITZ microstructure and its influences on effective elastic properties and diffusivity of concrete. PhD Thesis Delft University of Technology, Delft (to be published).

Chen H, Stroeven P, Ye G, Stroeven M (2006). Influence of boundary conditions on pore percolation in model cement paste. Key Engr Mat 303:486-92.

Chen HS, Ye G, Stroeven P (2004). Computer simulation of structure of hydrated cement paste enclosed by interfacial transition zone in concrete. In: Setzer MJ, Palecki S, eds. International Conference on Durability of High Performance Concrete and Final Workshop of CONLIFE, Freiburg, AEDIFICATIO Publ, 133-44.

Delfiner P (1971). A generalization of the concept of size. J Microsc 95:203-16.

Dequiedt AS, Coster M, Chermant J-L, Jeulin D (2001). Towards a model of concrete mesostructure. Cem Concr Comp 23:289-97.

Diamond S (2000). Mercury porosimetry; an inappropriate method for the measurement of pore size distributions in cement-based materials. Cem Concr Res 30(10): 1517-25.

Diamond S, Huang J (2001). The ITZ in concrete - a different view based on image analysis and SEM observations. Cem Concr Res 23:179-88.

Diekkämper, R (1984). Ein Verfahren zur numerischen Simulation des Bruchund Verformungs-verhaltens spröder Werkstoffe, Ruhr Universität Bochum, Techn Wissensch Mitteil Inst Konstr Ingenieursbau 7.

Fatt I 1956. The network model of porous media. Petroleum Transp AIME 207:144-59 (part I); 160-3 (part II); 164-81 (part III).

Freudenthal AM (1950). The Inelastic Behavior of Engineering Materials and Structures. New York: Wiley.

Friendam S, Seaton N 1996. On the transport properties of anisotropic networks of capillaries. Wat Resources Res 32:339-47.

Gundersen HJG, Jensen EB (1985). Stereological estimation of the volume-weighted mean volume of arbitrary particles observed on random sections. J Microsc 138:127-42.

He H, Hu J, Stroeven P, Guo Z, Stroeven M (2006). Assessment by computer simulation of geometric features of unhydrated cement that governs the selfhealing capacity of concrete. Sec Intern Symp Advances in concrete through science and engineering, 11-13 Sept, Quebec.

Hilfer R (1992). Local porosity theory for flow in porous media. Phys Rev B 45:7115-21.

Holliday L (1966). Geometric consideration and phase relationships. In: Holliday L, ed. Composite Materials. Amsterdam: Elsevier Publ, 1-27.

Hu J, Stroeven P (2003). Application of image analysis to assessing critical pore size for permeability prediction on cement paste. Im Anal Stereol 22(2):97-103.

Hu J, Stroeven P (2004). Porosity of concrete; morphological study of model concrete. PhD Thesis, Delft University of Technology, Delft.

Hu J, Stroeven P (2005a). Local porosity analysis of pore structure in cement paste. Cem Concr Res 35(2):23342.

Hu J, Stroeven P (2005b). Size effect in structural analysis of cementitious materials. In: Chraponski J, Cwajna J, Wojnar L, eds. Proceedings of $9^{\text {th }}$ European Congress on Stereology and Image Analysis. Krakow: Polish Society for Stereology, 23-30.

Hu J, Stroeven P (2005c). Depercolation threshold of porosity in model cement; approach by morphological evolution during hydration. Cem Concr Comp 27(1): 19-25.

Hu J, Stroeven P (2005d). Size characterization of pore structure for estimating transport properties of cement paste. Heron 50;1:41-54.

Hu J, Stroeven P (2006). Proper characterization of pore size distribution in cementitious materials. Key Engr Mat 302:19-25.

Jeulin D (2000). Random texture models for material structures. Stat Comp10:21-32.

Lange DA, Jennings HM, Shah SP (1994). Image analysis techniques for characterization of pore structure of cement-based materials. Cem Concr Res 24(5):841-53.

Kendall MG, Moran PAP (1963). Geometrical Probability. London: Griffin \& Co.

Meakawa K, Chaube R, Kishi T (1999). Modeling of concrete performance - hydration, microstructure formation and mass transport. London: E\&FN Spon.

Philipse AP (1996). The random contact equation and its implications for (colloidal) rods in packings, suspensions, and anisotropic powders. Langmuir 12:1127-33

Roelfstra PE (1989). A numerical approach to investigate 
the properties of numerical concrete. $\mathrm{PhD}$ Thesis, EPFL-Lausanne, Lausanne.

Scrivener KL (1989). The use of backscattered electron microscopy and image analysis to study the porosity of cement paste. In: Roberts LR, Skalny JP, eds. Proceedings of Material Research Society Symposium 137. Boston: MRS 129-40.

Scrivener KL, Nemati KM (1995). The percolation of pore space in the cement paste/aggregate interfacial zone of concrete. Cem Concr Res 26:35-40.

Serra J (1982). Image analysis and mathematical morphology. London: Academic Press.

Stroeven M (1999). Discrete Numerical Model for the Structural Assessment of Composite Materials. PhD Thesis, Delft University Press, Delft.

Stroeven P (2003). Implications of the law of aggregation of matter in concrete technology. In: Brandt AM, Li VC, Marshall IH, eds. Proceedings Brittle Matrix Composite 7. Cambridge: Woodhead Publ, 129-42.

Stroeven P (2005). Design of experiments in concrete technology: influx of materials science and stereology. In: Chraponski J, Cwajna J, Wojnar L, eds. Proceedings of $9^{\text {th }}$ European Congress on Stereology and Image Analysis. Krakow: Polish Society for Stereology, 44-54.

Stroeven M, Stroeven P (1996). Computer-simulated internal structure of materials. Acta Stereol 15(3):247-52.

Stroeven M, Stroeven P (1997). Simulation of hydration and the formation of microstructure. In: Owen, D.R.J., Oñate, E., Hinton, E eds. Computational Plasticity. Barcelona: CIMNE, 981-7.

Stroeven P, Stroeven M (1999). Assessment of packing characteristics by computer simulation. Cem Concr Res 29:1201-6.

Stroeven P, Stroeven M (2000). Assessment of particle packing characteristics at interfaces by SPACE system. Im Anal Stereol 19:85-90.

Stroeven P, Stroeven M (2001a). SPACE approach to concrete's space structure and it's mechanical properties. Heron 46(4):265-89.
Stroeven P, Stroeven M (2001b). Reconstruction by SPACE of the interfacial transition zone. Cem Concr Comp 23:189-200.

Stroeven P, Stroeven M (2001c). Size of representative volume element of concrete assessed by quantitative image analysis and computer simulation. Im Anal Stereol 20(suppl 1):216-20.

Stroeven P, Hu J, Stroeven M (2006a). Exploitation of particle migration mechanism to promote economy and ecology in concrete technology. Key Engr Mat 302:19-25.

Stroeven P, Hu J, Guo Z, Stroeven M, Chen H, Sluys LJ (2006b). Development of reliable and economic methodology for modelling of concrete durability. Sec Intern Symp Advances in concrete through science and engineering, 11-13 Sept, Quebec.

Stroeven P, Sluys, LJ, Guo Z, Stroeven M (2006c). Virtual reality studies of concrete. Forma (submitted for publication on WEB).

Vogel HJ, Roth K (2001). Quantitative morphology and network representation of soil pore structure. Adv Water Resources 24:233-42.

Wang Y, Diamond S (1995). An approach to quantitative image analysis for cement pastes. In: Diamond $\mathrm{S}$, Mindess S, Glasser FP, Roberts LW, Skalny JP, Wakeley LD, eds. Microstructure of Cement Based Systems/Bonding and Interfaces in Cementitious Materials. Proceedings of Material Research Society 370. Pittsburgh: MRS, 23-32.

Williams SR, Philipse AP (2003). Random packings of spheres and spherocylinders simulated by mechanical contraction, Phys Rev E 67(051301):1-9.

Willis KL, Abell AB, Lange DA (1998). Image-based characterization of cement pore structure using Wood's metal intrusion. Cem Concr Res 28(12):1695-705.

Ye G, Breugel K van, Fraaij ALA (2003). Three-dimensional microstructure analysis of numerically simulated cementitious materials. Cem Concr Res 33:215-22. 